\title{
sciendo
}

\section{Spanish Elite Soccer Reserve Team Configuration and the Impact of Physical Fitness Performance}

\author{
by \\ Asier Los Arcos ${ }^{1}$, Raúl Martínez-Santos ${ }^{1}$, Daniel Castillo ${ }^{2}$
}

\begin{abstract}
The aim of this study was threefold: 1) to assess the configuration of an elite reserve soccer team, 2) to compare physical fitness performance of promoted and new players according to the playing position, and 3) to analyze the level of competitive participation attained by these players. We considered physical fitness tests $(5 \mathrm{~m}$ and $15 \mathrm{~m}$ sprint, countermovement jump [CMJ] and aerobic endurance) performed by 192 players (age $=20.2 \pm 2.3$ years) enrolled in the reserve team of a Spanish La Liga club from 1994 to 2013. The players were classified according to the previous club criterion (promoted from the soccer academy and new players signed from other clubs), b) their playing position, and c) the competitive level attained until the 2016/2017 season (Spanish 1st and 2nd Divisions and the remaining competition levels). The proportion of promoted and new players was similar $(p=0.47)$. Overall, no substantial differences (unclear-small) were found in physical fitness performance between promoted and new players. Considering the playing position, promoted lateral defenders $(L D s)$ showed better sprinting $(E S=$ moderate) and $C M J(E S=$ moderate) performance than new LDs. In addition, promoted central midfielders (CMs) demonstrated better performance in the $5 \mathrm{~m}$ sprint and the CMJ (ES = moderate) than new CMs. The percentage of players who later competed in the Spanish 1st and 2nd Divisions was greater in promoted players compared to new players ( $p=0.006)$. Physical fitness performance did not determine the selection of new players in a soccer elite reserve team. We may conclude that soccer academies should prioritize the selection and the training process of youth soccer players.
\end{abstract}

Key words: soccer, talent identification, neuromuscular performance, aerobic endurance.

\section{Introduction}

Previous research states that the opportunity for financial profit seems to influence the recruitment of players for the 1st team (Relvas et al., 2010). That is, the greater and the more successful a club is, the larger its budget for signing new players from other clubs (Bourke, 2003). Due to the hierarchical structure of the market of the production and consumption of soccer players (Bourke, 2003), many professional clubs, in much less wealthy situations, have founded soccer academies with the primary objective of developing players to the professional level (Mills et al., 2012). This may also reflect the shift from a market-based solution to the problem of finding skilled labor towards another one based on internal hierarchical arrangements (i.e., growyour-own policies) (Bourke, 2003). This option can be even more interesting in countries like Spain, where the poor financial wealth of the whole system (Barajas and Rodríguez, 2013) has increased the differences between the teams of the Spanish Liga.

Soccer academies consider both the training process to facilitate the highest performance progress of the players and the identification and selection of the most promising young talent (Güllich, 2014). Due to the fact that talent identification in soccer is a dynamic (Vaeyens et al., 2006) and complex (Reilly et al., 2000; Zuber et al, 2016) process that requires a multivariate approach (Reilly et al., 2000), the decisions made by technical staff and soccer

1 - Department of Physical Education and Sport, University of the Basque Country, Vitoria-Gasteiz, Spain.

2 - Facultad de Ciencias de la Salud, Universidad Isabel I, Calle de Fernán González, Burgos, Spain. 
scouts are very difficult. Expert coaches consider that both environmental and intrapersonal factors (i.e., resilience, goal-directed attributes, intelligence, and awareness) influence elite player development (Mills et al., 2012), but none of these, nor physical fitness performance, can be assessed in players in other clubs. At most, soccer scouts can estimate these factors based on their own subjective assessments of performance during the games and statistical reports produced by private (Barris and Button, 2008; Castellano et al., 2014; Sarmento et al., 2014) or institutional entities after matches at the top competitive level (i.e. technical, tactical and physical fitness performance variables).

One of the pivotal stages in soccer academies is the transition from the reserve team to high level soccer (Mills et al., 2012), this final period being critical in the progress of every player's career (Vaeyens et al., 2005). In these types of teams, as in previous training stages, the main aim is to optimize the soccer competence of players. However, managers of the soccer academies also give great value to attaining the highest possible competition level for their elite reserve players because the match is an important session within the training process. This usually requires the inclusion of complementary new players from other clubs in order to make the squad stronger and the project successful, and many soccer scouts, usually former professional soccer players, emphasize the importance of motor abilities (Christensen, 2009) in the selection of those players. However, no study has analyzed whether soccer scouts, in a subjective way (Dadelo et al., 2014; Williams and Reilly, 2000), attach any importance to physical fitness performance in the selection of elite-oriented soccer players who should be prepared to compete at the elite level in the near future.

Therefore, the aim of this study was threefold: 1) to assess the configuration of an elite reserve soccer team, 2) to compare the physical fitness performance of promoted and new players according to the playing position, and 3) to analyze the level of competitive participation attained by these players.

\section{Methods}

\section{Design and Participants}

This research was carried out in a Spanish
La Liga Club which has been running its own elite Academy since 1982. One hundred and ninetytwo young soccer players $(20.2 \pm 2.3$ years; body height $=1.80 \pm 0.06 \mathrm{~m}$; body mass $=74.2 \pm 6.0 \mathrm{~kg}$ ) belonging to the same reserve team of a Spanish La Liga club from 1994 to 2013 participated in this study. We considered any player that competed in the Spanish $3^{\text {rd }}$ Division (2 $\left.2^{\mathrm{a}}-\mathrm{B}\right)$ during that period, having played at least five games at this competitive level, and with a minimum of 8 years of soccer experience. All the included players were classified in two groups: a) promoted: players promoted from the soccer academy of the same club to the reserve team, and $b$ ) new players: players who were signed from other clubs to play in the reserve team. Moreover, players were classified in relation to their playing position (Bradley et al., 2009; Carling et al., 2012; Lago et al., 2010; Los Arcos and Martins, 2018): goalkeeper $(\mathrm{G})$, lateral defender (LD), central defender $(C D)$, lateral midfielder (LM), central midfielder (CM), and attacker (A). In addition, the competitive level attained by the 2016/2017 season by both promoted and new players was registered: Spanish $1^{\text {st }}$ and $2^{\text {nd }}$ Divisions and the remaining competition levels.

In addition, we were able to collect all the results of physical fitness tests (linear 5 and $15 \mathrm{~m}$ sprints, CMJ and an endurance running test), carried out in the period between the 1994/1995 and 2012/2013 seasons as part of the customary training process, in accordance to the protocol approved beforehand by the Institutional Review Committee of the Sports and Youth Institute of Navarre (Spain) and the Declaration of Helsinki (2013). For our purposes, we kept the mean value of all the tests performed by each player in their first year in the reserve team during the in-season period.

Firstly, we calculated the proportion of promoted and new players according to the playing position. Moreover, we analyzed the previous level of competition achieved by new players. Then, we compared physical fitness performance between promoted and new players: a) taking the 18 seasons together, $b$ ) according to three consecutive periods (Period $1(\mathrm{P} 1)=1994-$ 2000, Period $2(\mathrm{P} 2)=2000-2006$, Period $3(\mathrm{P} 3)=$ 2006-2012) (Castillo et al., 2018; Martínez-Santos et al., 2016; Tønnessen et al., 2013), and c) by the playing position. Finally, we compared the 
proportion of players in each group (promoted vs. new players) that eventually competed in Spanish professional elite soccer $\left(1^{\text {st }}\right.$ and $2^{\text {nd }}$ Spanish Divisions).

\section{Procedures}

According to the protocols established by the club, during the in-season period of each season $(\mathrm{T} 1=$ September-October $/ \mathrm{T} 2=$ DecemberJanuary / T3 = February-March / T4 = May-June), players completed four times a battery of physical fitness tests that included linear 5 and $15 \mathrm{~m}$ sprints, CMJ and an endurance running test. Before each testing session, a standardized warmup was performed consisting of 5-min lowintensity running, mobility exercises, strides and acceleration drills. The players were instructed to avoid any strenuous exercise in the 24 hours prior to this test session.

$15 \mathrm{~m}$ sprint test

The sprint test consisted of three maximal sprints over $15 \mathrm{~m}$ with a 2 min rest interval between each trial, giving enough time to walk back to the start line and wait for the next turn, as previously described by Gorostiaga et al. (2009) and Los Arcos et al. (2014). Players started the sprint $0.5 \mathrm{~m}$ behind the starting point. The time was measured with accuracy of $\pm 0.001 \mathrm{~s}$ by means of photocell gates (Microgate ${ }^{\circledR}$ Polifemo, Bolzano, Italy) placed $0.4 \mathrm{~m}$ above the ground. The timer, automatically activated as the participants crossed the first gate at the $0.0 \mathrm{~m}$ mark, recorded split times at 5 and $15 \mathrm{~m}$, and the fastest time taken for each distance (i.e. $5 \mathrm{~m}$ and $15 \mathrm{~m}$ ) was considered for further analysis.

\section{Countermovement jump}

The participants were asked to perform a maximal countermovement vertical jump on a jumping mat (Newtest OY, Oulu, Finland), with both hands fixed on the hips. The participants started the jump from an extended leg position, going down to $90^{\circ}$ knee flexion, immediately followed by a subsequent concentric action for maximal height and tried to land in a position as similar as possible to that at the take-off (Bosco et al., 1983). Jumping height was calculated from the flight time. Three attempts, with approximately 20 $\mathrm{s}$ rest intervals between jumps, were recorded. The best result was considered for further analysis.

Endurance running test

$$
\text { Participants performed a 4-stage }
$$

submaximal intermittent (i.e. 3-min recovery) running test around the soccer pitch $(100 \times 50 \mathrm{~m})$. The running speeds were $12 \mathrm{~km} \cdot \mathrm{h}^{-1}(10 \mathrm{~min}), 13$ $\mathrm{km} \cdot \mathrm{h}^{-1}(10 \mathrm{~min}), 14 \mathrm{~km} \cdot \mathrm{h}^{-1}(10 \mathrm{~min})$, and $15 \mathrm{~km} \cdot \mathrm{h}^{-1}$ (5 min), for the first, second, third, and fourth stages, respectively (Gorostiaga et al., 2009). Running speeds were dictated in the form of audio cues broadcast by a pre-programmed computer (Balise Temporelle, Bauman, Switzerland). Immediately after each exercise stage, after cleaning and puncturing, a $5 \mu \mathrm{L}$ sample of whole blood was automatically aspirated from the participant's hyperemized earlobe into a single-use enzyme-coated electrode test strip. [La] was determined via amperometric measurement and the result was displayed within $60 \mathrm{~s}$ by means of a portable lactate analyzer (Lactate Pro LT-1710; Arkray KDK Corporation, Shiga, Japan). In terms of reliability, the manufacturers report a coefficient of variation of $3.2 \%$ and $2.6 \%$ for lactate standard samples of 2 and $11 \mathrm{mmol} \cdot \mathrm{L}^{-1}$, respectively. The analyzer was calibrated according to the manufacturer's instructions before every test. The exercise lactate profile was obtained using the curve-of-best-fit procedure with a second-order polynomial function. From the equation describing the exercise blood lactate curve, the velocity associated with [La]b of $3 \mathrm{mmol} \cdot \mathrm{l}^{-1}\left(V_{3}\right)$ was intrapolated (Gorostiaga et al., 2004) and considered.

\section{Statistical Analysis}

Results are presented as mean \pm standard deviation (SD). A chi-square test was used to test the playing position and the distribution of the competitive level attained across the promoted and new players. Statistical significance was set at $p \leq 0.05$. In order to compare physical fitness performance between promoted and new players, practical significance was assessed by calculating the Cohen's d effect size (Cohen, 1988) with a modified statistical Excel spreadsheet provided by Hopkins (Hopkins, 2007). Effect sizes (ES) between < 0.2, 0.2-0.6, 0.6-1.2, 1.2-2, and 2.0-4.0 were considered trivial, small, moderate, large and very large, respectively (Hopkins et al., 2009). Probabilities were also calculated to establish whether the true (unknown) differences were lower, similar to or higher than the smallest worthwhile difference or change $(0.2 \mathrm{x}$ betweenparticipant SD, based on the Cohen's effect size 
principle). The quantitative chances of higher or lower differences were evaluated qualitatively as follows: $<1 \%$, almost certainly not; $1-5 \%$, very unlikely; 5-25\%, unlikely; 25-75\%, possible; 75-95\%, likely; 95-99\%, very likely; > 99\%, almost certain. If the chances of having higher or lower values than the smallest worthwhile difference were both $>5 \%$, the true difference was assessed as unclear.

\section{Results}

\section{Team Configuration}

Promoted players (18.7 \pm 1.5 years) were younger $(E S=1.87 ; \pm 0.3$, most likely large) than new players (21.6 \pm 2.1 years) in their first season in the reserve team. The proportion of promoted and new players was $48 \%$ (92 players: 8 GKs, 13 CDs, $18 \mathrm{LDs}, 22 \mathrm{CMs}, 12 \mathrm{LMs}$ and $19 \mathrm{As}$ ) and $52 \%$ (100 players: 7 GKs, 16 CDs, 18 LDs, 16 CMs, 16 LMs and $27 \mathrm{As})$ of the total, respectively $(p=0.47)$. The proportion of players in each playing position was similar in both promoted and new players $(p$ $=0.71$. .

Of the 100 new players signed by the Club, 50\% came from lower categories (< Spanish 3rd Division, 2-B) and the other $46 \%$ from the same category (i.e., Spanish 3rd Division, $2^{2}-\mathrm{B}$ ). Only $4 \%$ (4 players) of the new players had competed previously in a higher competition category, specifically in the Spanish $2^{\text {nd }}$ Division.

Table 1

Differences in sprinting and jumping performance and velocity associated with [La]b of $3 \mathrm{mmol} \cdot \mathrm{l}^{-1}\left(V_{3}\right)$ between promoted and new players in each period.

\begin{tabular}{|c|c|c|c|c|c|c|c|}
\hline Period & Test & $\begin{array}{c}\text { Promoted } \\
\text { players }\end{array}$ & $\mathrm{n}$ & $\begin{array}{c}\text { New } \\
\text { players }\end{array}$ & $\mathrm{n}$ & ES; CL 90\% & Magnitude based inference \\
\hline
\end{tabular}

\begin{tabular}{|c|c|c|c|c|c|c|c|c|}
\hline \multicolumn{9}{|l|}{$1994-2000$} \\
\hline & $5 m(\mathrm{~s})$ & $0.95 \pm 0.02$ & 26 & $0.95 \pm 0.03$ & 15 & $0.03 ; \pm 0.63$ & $32 / 41 / 27$ & Unclear \\
\hline & $15 m(\mathrm{~s})$ & $2.28 \pm 0.06$ & 27 & $2.27 \pm 0.06$ & 15 & $-0.17 ; \pm 0.51$ & $11 / 42 / 46$ & Unclear \\
\hline & $C M J(\mathrm{~cm})$ & $45.43 \pm 4.65$ & 27 & $44.69 \pm 3.62$ & 16 & $-0.15 ; \pm 0.45$ & $10 / 47 / 43$ & Unclear \\
\hline & $V_{3}\left(\mathrm{~km} \cdot \mathrm{h}^{-1}\right)$ & $12.56 \pm 0.56$ & 16 & $12.87 \pm 0.82$ & 10 & $0.52 ; \pm 0.89$ & $73 / 18 / 9$ & Unclear \\
\hline \multirow[t]{4}{*}{ 2000-2006 } & $5 m(\mathrm{~s})$ & $0.95 \pm 0.02$ & 36 & $0.97 \pm 0.04$ & 28 & $0.53 ; \pm 0.59$ & $82 / 15 / 2$ & Likely small \\
\hline & $15 m(\mathrm{~s})$ & $2.30 \pm 0.04$ & 36 & $2.30 \pm 0.07$ & 28 & $0.17 ; \pm 0.63$ & $47 / 37 / 17$ & Unclear \\
\hline & $C M J(\mathrm{~cm})$ & $45.65 \pm 3.91$ & 36 & $45.03 \pm 4.26$ & 27 & $-0.15 ; \pm 0.44$ & $9 / 48 / 49$ & Unclear \\
\hline & $V_{3}\left(\mathrm{~km} \cdot \mathrm{h}^{-1}\right)$ & $12.55 \pm 0.66$ & 34 & $12.48 \pm 0.81$ & 24 & $-0.10 ; \pm 0.50$ & $16 / 47 / 37$ & Unclear \\
\hline \multirow[t]{4}{*}{ 2006-2012 } & $5 m(\mathrm{~s})$ & $0.96 \pm 0.03$ & 29 & $0.97 \pm 0.02$ & 58 & $0.38 ; \pm 0.36$ & $80 / 19 / 0$ & Likely small \\
\hline & $15 m(\mathrm{~s})$ & $2.30 \pm 0.05$ & 29 & $2.32 \pm 0.06$ & 58 & $0.41 ; \pm 0.37$ & $82 / 17 / 0$ & Likely small \\
\hline & $C M J(\mathrm{~cm})$ & $44.47 \pm 4.14$ & 29 & $42.83 \pm 4.58$ & 58 & $-0.38 ; \pm 0.38$ & $1 / 21 / 79$ & Likely small \\
\hline & $V_{3}\left(\mathrm{~km} \cdot \mathrm{h}^{-1}\right)$ & $12.39 \pm 0.61$ & 25 & $12.54 \pm 0.89$ & 46 & $0.25 ; \pm 0.47$ & $57 / 37 / 6$ & Unclear \\
\hline
\end{tabular}

Legend: $E S=$ effect size; $C L=$ confidence limits. 


\begin{tabular}{|c|c|c|c|c|c|c|c|c|}
\hline \multirow{3}{*}{$\begin{array}{c}\text { Player } \\
\text { Position } \\
\text { G }\end{array}$} & \multicolumn{8}{|c|}{$\begin{array}{c}\text { Table } 2 \\
\text { Differences in sprinting and jumping performance and velocity associated } \\
\text { with [La]b of } 3 \mathrm{mmol} \mathrm{l}^{-1}\left(\mathrm{~V}_{3}\right) \text { between promoted and new players by playing position. }\end{array}$} \\
\hline & \multirow{2}{*}{ Test } & \multirow{2}{*}{$\begin{array}{c}\begin{array}{c}\text { Promoted } \\
\text { players }\end{array} \\
0.94 \pm 0.03\end{array}$} & \multirow{2}{*}{ n } & \multirow{2}{*}{$\begin{array}{c}\text { New } \\
\text { players }\end{array}$} & \multirow{2}{*}{ n } & \multirow{2}{*}{$\begin{array}{c}\text { ES; CL } 90 \% \\
0.55 ; \pm 0.82\end{array}$} & \multicolumn{2}{|c|}{ Magnitude based inference } \\
\hline & & & & & & & $77 / 17 / 6$ & Unclear \\
\hline & $15 m(\mathrm{~s})$ & $2.28 \pm 0.08$ & 8 & $2.31 \pm 0.09$ & 7 & $0.35 ; \pm 0.85$ & $62 / 24 / 14$ & Unclear \\
\hline & $C M J(\mathrm{~cm})$ & $45.71 \pm 6.10$ & 8 & $44.08 \pm 4.46$ & 7 & $-0.24 ; \pm 0.71$ & $15 / 32 / 54$ & Unclear \\
\hline \multirow{4}{*}{ LD } & $5 m(\mathrm{~s})$ & $0.95 \pm 0.02$ & 18 & $0.97 \pm 0.03$ & 17 & $1.03 ; \pm 0.71$ & $97 / 2 / 0$ & Very likely moderate \\
\hline & $15 m(\mathrm{~s})$ & $2.27 \pm 0.04$ & 18 & $2.32 \pm 0.06$ & 17 & $1.18 ; \pm 0.68$ & $99 / 1 / 0$ & Very likely moderate \\
\hline & $C M J(\mathrm{~cm})$ & $46.27 \pm 4.15$ & 18 & $43.51 \pm 4.28$ & 17 & $-0.63 ; \pm 0.55$ & $1 / 9 / 91$ & Likely moderate \\
\hline & $V 3\left(\mathrm{~km} \cdot \mathrm{h}^{-1}\right)$ & $12.49 \pm 0.63$ & 16 & $12.60 \pm 1.15$ & 13 & $0.17 ; \pm 0.84$ & $48 / 29 / 23$ & Unclear \\
\hline \multirow[t]{4}{*}{$\mathrm{CD}$} & $5 m(\mathrm{~s})$ & $0.96 \pm 0.02$ & 13 & $0.97 \pm 0.03$ & 16 & $0.95 ; \pm 0.79$ & $94 / 5 / 1$ & Likely mdoerate \\
\hline & $15 m(\mathrm{~s})$ & $2.30 \pm 0.04$ & 13 & $2.32 \pm 0.07$ & 16 & $0.41 ; \pm 0.76$ & $68 / 23 / 9$ & Unclear \\
\hline & $C M J(\mathrm{~cm})$ & $45.06 \pm 3.79$ & 13 & $43.60 \pm 4.57$ & 16 & $-0.36 ; \pm 0.65$ & $8 / 26 / 66$ & Unclear \\
\hline & $V 3\left(\mathrm{~km} \cdot \mathrm{h}^{-1}\right)$ & $12.64 \pm 0.81$ & 11 & $12.50 \pm 0.70$ & 13 & $-0.15 ; \pm 0.61$ & $17 / 39 / 45$ & Unclear \\
\hline \multirow[t]{4}{*}{ LM } & $5 m(s)$ & $0.95 \pm 0.02$ & 12 & $0.95 \pm 0.03$ & 16 & $0.11 ; \pm 0.66$ & $40 / 38 / 22$ & Unclear \\
\hline & $15 m(\mathrm{~s})$ & $2.28 \pm 0.05$ & 12 & $2.28 \pm 0.06$ & 16 & $0.01 ; \pm 0.72$ & $32 / 36 / 31$ & Unclear \\
\hline & $C M J(\mathrm{~cm})$ & $44.19 \pm 4.06$ & 12 & $43.94 \pm 4.67$ & 16 & $-0.06 ; \pm 0.65$ & $25 / 39 / 36$ & Unclear \\
\hline & $V 3\left(\mathrm{~km} \cdot \mathrm{h}^{-1}\right)$ & $12.85 \pm 0.50$ & 11 & $12.99 \pm 0.90$ & 12 & $0.26 ; \pm 0.97$ & $54 / 25 / 21$ & Unclear \\
\hline \multirow[t]{4}{*}{$\mathrm{CM}$} & $5 m(\mathrm{~s})$ & $0.96 \pm 0.02$ & 22 & $0.98 \pm 0.03$ & 16 & $0.60 ; \pm 0.66$ & $85 / 13 / 2$ & Likely moderate \\
\hline & $15 m(\mathrm{~s})$ & $2.32 \pm 0.05$ & 22 & $2.33 \pm 0.07$ & 16 & $0.17 ; \pm 0.65$ & $47 / 36 / 17$ & Unclear \\
\hline & $C M J(\mathrm{~cm})$ & $44.25 \pm 3.46$ & 22 & $41.14 \pm 3.87$ & 16 & $-0.87 ; \pm 0.58$ & 0/3/97 & Very likely moderate \\
\hline & $V 3\left(\mathrm{~km} \cdot \mathrm{h}^{-1}\right)$ & $12.47 \pm 0.46$ & 19 & $12.40 \pm 0.78$ & 12 & $-0.15 ; \pm 0.91$ & $25 / 28 / 46$ & Unclear \\
\hline \multirow[t]{4}{*}{ A } & $5 m(\mathrm{~s})$ & $0.96 \pm 0.03$ & 19 & $0.97 \pm 0.03$ & 27 & $0.27 ; \pm 0.46$ & $59 / 36 / 5$ & Possibly small \\
\hline & $15 m(s)$ & $2.29 \pm 0.04$ & 19 & $2.30 \pm 0.05$ & 27 & $0.24 ; \pm 0.53$ & $55 / 37 / 8$ & Unclear \\
\hline & $C M J(\mathrm{~cm})$ & $45.86 \pm 4.60$ & 19 & $44.91 \pm 4.41$ & 27 & $-0.20 ; \pm 0.48$ & $9 / 42 / 50$ & Unclear \\
\hline & $V 3\left(\mathrm{~km} \cdot \mathrm{h}^{-1}\right)$ & $12.24 \pm 0.62$ & 19 & $12.46 \pm 0.71$ & 27 & $0.34 ; \pm 0.52$ & $67 / 28 / 4$ & Possibly small \\
\hline \multicolumn{9}{|c|}{$\begin{array}{c}\text { Legend: } E S=\text { effect size; } C L=\text { confidence limits; } G=\text { Goalkeepers; } L D=\text { Lateral defender; } \\
C D=\text { Central defender, } L M=\text { Lateral midfielders; } C M=\text { Central midfielders; } A=\operatorname{Attackers~}(A) .\end{array}$} \\
\hline
\end{tabular}

\section{Promoted vs. New Players by Periods}

Taking the three periods together, the differences between promoted and new players were small in the $5 \mathrm{~m}$ (promoted vs. new players; $0.95 \pm 0.03$ vs. $0.97 \pm 0.03 ; \mathrm{ES}=0.55 ; \pm 0.26 ; 99 / 1 / 0$, very likely) and in the $15 \mathrm{~m}(2.29 \pm 0.05$ vs. $2.31 \pm$ 0.06 ; $\mathrm{ES}=0.35 ; \pm 0.27 ; 82 / 17 / 0$, likely) sprint times, as well as in the CMJ $(45.21 \pm 4.20$ vs. $43.62 \pm 4.44$; $\mathrm{ES}=-0.38 ; \pm 0.24 ; 0 / 12 / 88$, likely). Besides, the differences in the velocity associated with $[\mathrm{La}]_{\mathrm{b}}$ of $3 \mathrm{mmol} \cdot \mathrm{l}^{-1}\left(V_{3}\right)$ were unclear $(12.50 \pm 0.62$ vs. 12.57 $\pm 0.85, \mathrm{ES}=0.11 ; \pm 0.32$ ).

According to those periods, promoted players showed better performance than new players in sprinting and jumping (ES = likely small) in the third period, differences being unclear in the remaining periods (i.e., P1 and P2) (Table 1). The differences in the $V_{3}$ were unclear in all periods.

Promoted vs. New Players by Playing Position

No substantial differences were found in physical fitness performance between promoted and new players for Gs and LMs, although promoted LDs showed very likely moderate better sprinting performance ( 5 and $15 \mathrm{~m}$ sprint times) than new players $(E S=1.03-1.18)$ and their performance in the CMJ was also likely and moderately higher. In addition, performances in 
the $5 \mathrm{~m}$ sprint and CMJ tests were likely/very likely and moderately $(E S=0.60-0.87)$ higher in promoted CMs than in new CMs (Table 2).

\section{Promotion to Elite Soccer}

Significant differences $(p=0.006)$ were found between promoted and new players in the proportion attaining the competitive level. While $43 \%$ of the promoted players eventually competed in Spanish professional soccer ( $1^{\text {st }}$ Division: 29\%; $2^{\text {nd }}$ Division: $14 \%$ ), the proportion was just $30 \%$ for the new players (1 ${ }^{\text {st }}$ Division: $11 \% ; 2^{\text {nd }}$ Division: $19 \%$ ).

\section{Discussion}

The aim of this study was threefold: 1) to assess the configuration of an elite reserve soccer team, 2) to compare the physical fitness performance of promoted and new players according to the playing position, and 3) to analyze the level of competitive participation attained by these players. The main findings were: a) overall, and according to the playing position, the proportions of promoted and new players were similar, b) physical fitness performance (sprinting, jumping and aerobic fitness) was similar in promoted and new players, but, according to the playing positions, promoted LDs, $\mathrm{CD}$ and $\mathrm{CMs}$ players had substantially (ES = moderate) higher sprinting and jumping capacities than new players, and c) the players promoted from the junior team of the Club were more successful. These results highlight how important investing in soccer academies can be, and that physical fitness performance does not seem to determine the selection of new players for a soccer elite reserve team.

Team configuration

The high percentage of new players $(52 \%$ of the total players of the elite reserve team during the 18 seasons) may be due to the need to sign players with greater soccer expertise in order to maintain the competition level (Spanish 2nd Division-B) of the reserve team. Unfortunately, we cannot compare this proportion because, to our knowledge, no similar studies are available. The distribution of promoted and new players by their playing position was similar. Although the need for players in each playing position can vary from season to season, depending on the market opportunities and the characteristics of players who are promoted from the junior team, in the long term, the playing position was not relevant to being promoted or signed from other teams.

Promoted vs. New Players by Periods

Both when taking the whole period together and after analysis of the three periods separately (P1: 1994-2000; P2: 2000-2006 and P3: 2006-2012), the differences in physical fitness performance between promoted and new players were unclear-small (Table 1). These results suggest that physical fitness performance does not determine the selection of new players for an elite reserve team, and that this criterion, assessed subjectively, has not varied over the years. Although some match running demands have increased over the 2006-2012 period in European elite soccer (Barnes et al., 2014; Bush et al., 2015), physical fitness performance of new players was not any better than that of players promoted from the junior team during this period. It is possible that soccer scouts continued to value highly other factors, such as "game intelligence" and "personal qualities" (Christensen, 2009), in their selection of new senior players. They could have emphasized team sports time management (anticipation and decision making (Williams and Reilly, 2000)) rather than physical fitness (acceleration capacity). Besides, physical fitness performance of players who have already passed a selection process every season (Bidaurrazaga-Letona et al., 2017) was considerably high (Castillo et al., 2018; Martínez-Santos et al., 2016).

Promoted vs. New Players by Playing Position

It was found that a higher profile in sprinting and jumping (assessed by $5 \mathrm{~m}, 15 \mathrm{~m}$ and $\mathrm{CMJ}$ ) can be an advantage for CDs, but not for the other playing positions, in terms of their promotion from an elite soccer reserve team to the top level of soccer in Spain (Martínez-Santos et al., 2016). However, scouts did not select faster and more powerful defenders in comparison to promoted players. Performance in the $5 \mathrm{~m}$ sprint was likely and moderately $(\mathrm{ES}=0.95 ; \pm 0.79)$ higher in promoted CDs than in new CDs (Table 2). In addition, differences between promoted and new players in lactate concentration at selected running speeds were unclear in almost all playing positions. Soccer scouts did not select players with higher aerobic endurance performance (i.e., V3) in comparison to promoted players, but a previous study showed that this physical dimension seemed not to be relevant to access 
professionalism from a reserve team in Spain (Castillo et al., 2018). Although the budget of the club limits the options of recruitment of players (Relvas et al., 2010), these results suggest that soccer scouts could seek a different type of player, possibly a better player from the tactical point of view.

\section{Promotion to Elite Soccer}

Interestingly, the odds of getting to play at the professional competitive-level were different for promoted and new players: while $43 \%$ of the players who were promoted within the club competed later in Spanish professional soccer (i.e., Spanish 1st and 2nd Divisions), only $30 \%$ of the new players achieved the professional standard of play. This difference is more acute if we consider how many of those professionals got to play in the 1st Division, two out of three of the promoted ones, but only one out of three of the signed ones: that means double chances for promoted players. These results point to the relevance of both the training process and the identification and selection of the most promising young talent (Güllich, 2014), especially before the senior category, in order to reduce the hierarchical structure of the market (Bourke, 2003).

It can be concluded that physical fitness performance does not determine the selection of players for elite reserve teams. Soccer scouts subjectively ascribe more importance to other soccer factors than physical abilities of players. Since the success ratio was higher in players promoted from the high-level soccer academy than in adult players signed from other clubs, soccer academies should prioritize the selection and the training process of youth soccer players.

\section{Acknowledgements}

The authors would like to thank the collaboration of the Centre of Studies, Research and Sports Medicine (CEIMD) in Pamplona (Spain) for the conduction of the physical tests..

\section{References}

Barajas Á, Rodríguez P. Spanish football in need of financial therapy: cut expenses and inject capital. IJSF, 2013; 9: 73-90

Barnes C, Archer DT, Hogg B, Bush M, Bradley PS. The evolution of physical and technical performance parameters in the English Premier League. Int J Sports Med, 2014; 35: 1095-1100

Barris S, Button C. A review of vision-based motion analysis in sport. Sports Med, 2008; 38: 1025-1043

Bidaurrazaga-Letona I, Lekue JA, Amado M, Gil SM. Progression in youth soccer: selection and identification in youth soccer players aged 13-15 years. J Strength Cond Res, 2017 [Epub ahead of print]

Bosco C, Luhtanen P, Komi PV. A simple method for measurement of mechanical power in jumping. Eur J Appl Physiol Occup Physiol, 1983; 50: 273-282

Bourke A. The dream of being a professional soccer player: Insight on career development options of young Irish players. J Sport Soc Issues, 2003; 27: 399-419

Bradley PS, Sheldon W, Wooster B, Olsen P, Boanas P, Krustrup, P. High-intensity running in English FA Premier League soccer matches. J Sports Sci, 2009; 27: 159-168

Bush M, Barnes C, Archer DT, Hogg B, Bradley PS. Evolution of match performance parameters for various playing positions in the English Premier League. Hum Mov Sci, 2015; 39: 1-11

Carling C, Le Gall F, Dupont G. Analysis of repeated high-intensity running performance in professional soccer. J Sports Sci, 2012; 30: 325-336

Castellano J, Alvarez-Pastor D, Bradley PS. Evaluation of research using computerised tracking systems (Amisco and Prozone) to analyse physical performance in elite soccer: a systematic review. Sports Med, 2014; 44: 701-712

Castillo D, Los Arcos A, Martinez-Santos R. Aerobic endurance performance does not determine the professional career of elite youth soccer players. J Sports Med Phys Fitness, 2018; 58: 392-398

Christensen MK. Articles "An Eye for Talent": Talent Identification and the "Practical Sense" of Top-Level Soccer Coaches. Sociol Sport J, 2009; 26: 365-382

Cohen J. Statistical power analysis for the behavioral sciences. Hillsdale: N.J.: L. Erlbaum Associates; 1988 
Dadelo S, Turskis Z, Zavadskas EK, Dadeliene R. Multi-criteria assessment and ranking system of sport team formation based on objective-measured values of criteria set. Expert Syst Appl, 2014; 41: 6106-6113

Gorostiaga EM, Izquierdo M, Ruesta M, Iribarren J, González-Badillo JJ, Ibáñez J. Strength training effects on physical performance and serum hormones in young soccer players. Eur J Appl Physiol, 2004; 91: 698707

Gorostiaga EM, Llodio I, Ibáñez J, Granados C, Navarro I, Ruesta M., Bonnabau H, Izquierdo M. Differences in physical fitness among indoor and outdoor elite male soccer players. Eur J Appl Physiol, 2009; 106: 483-491

Güllich A. Selection, de-selection and progression in German football talent promotion. Eur J Sport Sci, 2014; 14: 530-537

Hopkins W. A spreadsheet for deriving a confidence interval, mechanistic inference and clinical inference from a p value. Sportscience, 2007; 11: 16-20

Hopkins WG, Marshall SW, Batterham AM, Hanin J. Progressive statistics for studies in sports medicine and exercise science. Med Sci Sports Exerc, 2009; 41: 3-13

Lago C, Casais L, Dominguez E, Sampaio J. The effects of situational variables on distance covered at various speeds in elite soccer. Eur J Sport Sci, 2010; 10: 103-109

Los Arcos A, Martins J. Physical Fitness Performance of Young Professional Soccer Players Does not Change During Several Training Seasons in A Spanish Elite Reserve Team: A Club Study, 1996-2013. J Strength Cond Res, 2018; 32: 277-2583

Los Arcos A, Yanci J, Mendiguchia J, Salinero JJ, Brughelli M, Castagna C. Short-term training effects of vertically and horizontally oriented exercises on neuromuscular performance in professional soccer players. Int J Sports Physiol Perform, 2014; 9: 480-488

Martínez-Santos R, Castillo D, Los Arcos A. Sprint and jump performances do not determine the promotion to professional elite soccer in Spain, 1994-2012. J Sports Sci, 2016; 34: 2279-2285

Mills A, Butt J, Maynard I, Harwood C. Identifying factors perceived to influence the development of elite youth football academy players. J Sports Sci, 2012; 30: 1593-1604.

Reilly T, Williams AM, Nevill A, Franks AA. multidisciplinary approach to talent identification in soccer. J Sports Sci, 2000; 18: 695-702

Relvas H, Littlewood M, Nesti M, Gilbourne D, Richardson D. Organizational Structures and Working Practices in Elite European Professional Football Clubs: Understanding the Relationship between Youth and Professional Domains. Eur Sport Manag Q, 2010; 10: 165-187

Sarmento H, Marcelino R, Anguera MT, CampaniÇo J, Matos N, LeitÃo J.C. Match analysis in football: a systematic review. J Sports Sci, 2014; 32: 1831-1843

Tønnessen E, Hem E, Leirstein S, Haugen T, Seiler S. Maximal aerobic power characteristics of male professional soccer players, 1989-2012. Int J Sports Physiol Perform, 2013; 8: 323-329

Vaeyens R, Coutts A, Philippaerts RM. Evaluation of the «under-21 rule»: do young adult soccer players benefit? J Sports Sci, 2005; 23: 1003-1012

Vaeyens R, Malina RM, Janssens M, Van Renterghem B, Bourgois J, Vrijens J, Philippaerts RM. A multidisciplinary selection model for youth soccer: the Ghent Youth Soccer Project. Br J Sports Med, 2006; 40: 928-934

Williams AM, Reilly T. Talent identification and development in soccer. J Sports Sci, 2000; 18: 657-667

Zuber C, Zibung M, Conzelmann A. Holistic Patterns as an Instrument for Predicting the Performance of Promising Young Soccer Players - A 3-Years Longitudinal Study. Front Psychol, 2016; 7: 1088

\section{Corresponding author:}

\section{Asier Los Arcos Larumbe, PhD.}

Department of Physical Education and Sport,

University of the Basque Country, UPV/EHU, Vitoria-Gasteiz, Spain.

Lasarte 71, 01007 Vitoria-Gasteiz, Spain.0034 945013519

E-mail: asier.losarcos@ehu.eus 